\title{
One-Stage Rehabilitation of The Brush in Osteoblestklistoma Iii Metacarpal Bone Right Hand
}

\author{
Huseynov ZKh* \\ Department of Cancer Research Center, Ministry of Health and Social Development of the Republic of Tajikistan, Russia
}

*Corresponding author : Huseynov ZKh, Department of Cancer Research Center,

Ministry of Health and Social Development of the Republic of Tajikistan, Russia.

Received Date: May 222019

Published Date: May 28, 2019

\section{Abstract}

The article describes the case of successful single-stage substitution of sub-total defect III metacarpal bone graft III metatarsal bone after radical sub-total resection of the affected area Distal part of the 3rd metacarpal bone, due to osteoblastristoma. The peculiarity of this case is the momentary substitution of the defect of the distal joint head of the 3rd metacarpal bone with the help of a similar Graft III metatarsal bone. Radical resection of the unit of the affected sub-total segment of the metacarpal bone allows to minimize the risk of local relapse. One-moment compensation of the defect in the same Graft III metatarsal bone allows not only to restore the lost anatomy, but also to achieve the desired cosmetic and functional effect.

Keywords: Osteoblastoclastoma; Resection of the affected segment of metacarpal bone; Avascular bone-articular autograft of the metatarsal bone; Reconstruction of the bone defect of the metacarpal bone.

\section{Introduction}

The actuality. The giant tumor lesion of the bones or osteoclstomoma refers to a group of benign tumors with a local aggressive current [1]. The tumor is rarely localized in the metacarses with a frequency ranging from $1 \%$ to $5.5 \%$ of cases [2].

The lesion of the metacarpals is accompanied by excessive destruction of bone tissue and is more common at a young age, while other localizations affect people at older ages [1,2]. The tumor can affect any metacarhip bone and, as a rule, does not go beyond its bony-articular limits. Patients are more often treated during the period when the tumor spreads beyond $3-6 \mathrm{~cm}$ on the length of the metacarpal bone, with the presence of volumetric formation with globular or ellipsoid contour without perirest reaction $[3,4]$. Local relapse after Curettage tumor with subsequent/or without bone plastics have a tendency to relapse with a probability of up to $90 \%$ [3-6]. In this regard, the block radical resection of the tumor within the healthy bone tissue is a common standard of treatment [3-6]. After radical resection of the affected block of metacarpal bone there is a problem of its substitution. The involvement of one or both joint heads of metacarpal bone in the process poses a difficult task for the surgeon in choosing the optimal transplant for the rehabilitation of the brush function. At present, in such cases, the autografts, Allo-or Xeno grafts are used [5-15]. The article describes the case of substitution of the metacarpal bone defect with the involvement of the distal joint head with the help of bonearticular autograft III metatarsal bone.

\section{Materials and Methods}

A young patient aged 21 years with sub-total destruction III was admitted to the Clinic of reconstructive Surgery of the Republican Scientific-Clinical center of Cardiovascular Surgery. Metacarpal bone with the involvement of the distal joint head. X-rays, magnetic resonance imaging, puncture biopsy were performed for the purpose of diagnostics. The tactic of treatment was discussed by the staff of the Republican Oncology dispensary together with the specialists of the Department.

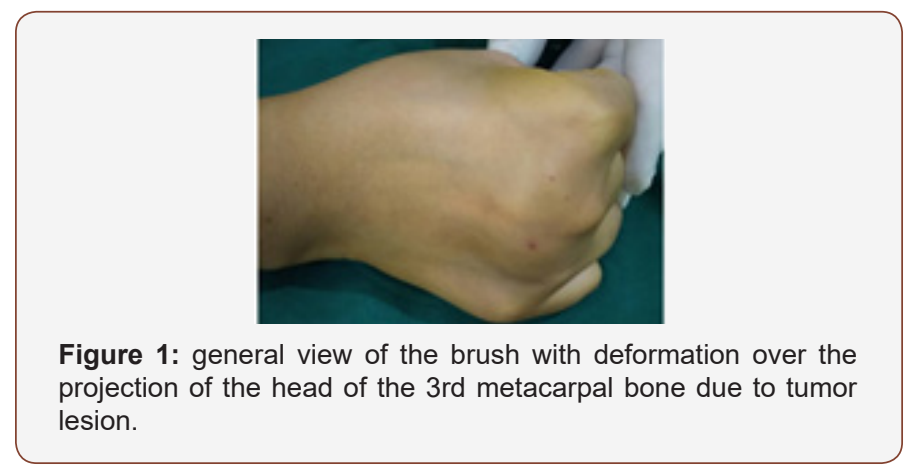


The stationary tumor formation of spherical-epileptoid form of firm consistence in diameter about $3.5 \mathrm{sm}$ (Figure 1) is determined locally. On the layered pictures. The almost complete destruction of the distal joint head of the 3Rd metacarpal bone of the right hand with the defeat of the Diophone with the spread of the tumor during $3.5 \mathrm{~cm}$ (Figure 2) was established.

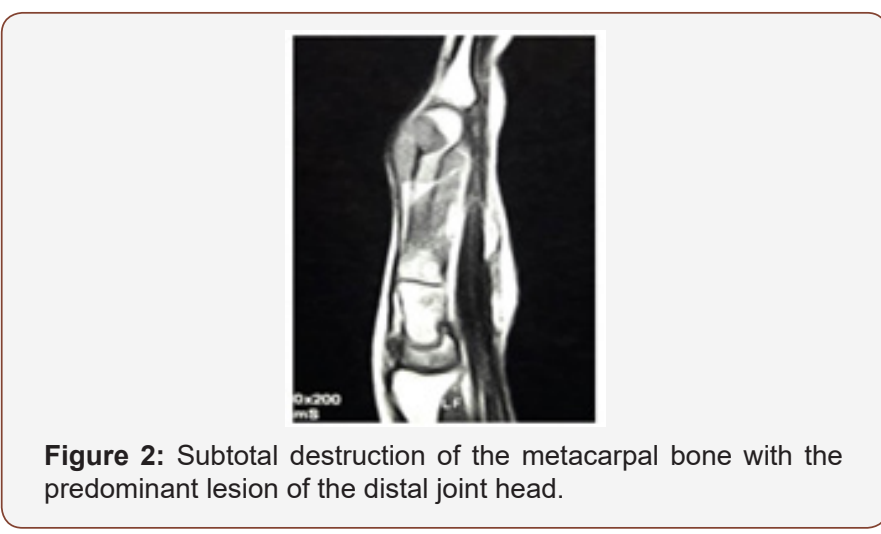

\section{Result}

After careful determination of the volume of lesion of the 3rd metacarpal Bone, a surgery consisting of the following elements was planned:

a. Sub-total resection of the 3rd metacarpal bone together with distal joint head;

b. One-moment replacement of defect by bone-articular autograft III metatarsal bone from the right foot;

c. Fixation of bone graft to the proximal part III of the metacarpal bone, the spoke of Kirshner;

d. Fixation of the third finger of the donor foot zone.

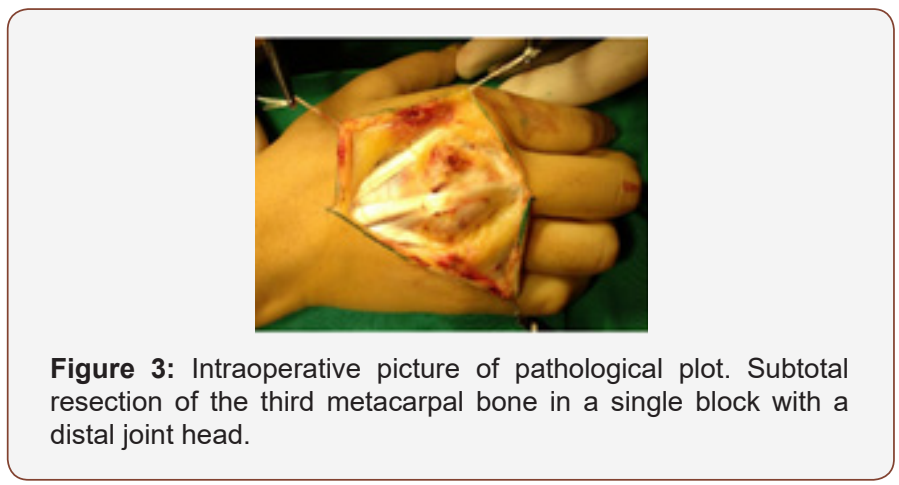

Under the general ETN the operation with involvement of 2 brigades of surgeons is executed. In the donor zone, the brigade of oncologists with a zigzag layer of $7 \mathrm{~cm}$ began to allocate a block of the affected metacarpal bone of the right bone (Figure 3,4). After the full mobilization of the metacarpal with the dissection of the heel-phalange capsule and the mobilization of the distal joint head with an indentation of $1.5 \mathrm{~cm}$ from the edge of the tumor with the help of a saw Jigley, the affected bone is reseccioned. On the stump of the base of the metacarpal bone a healthy tissue with the uninjured bone marrow was determined. The length of the cut-out block of the metacarpal bone together with the joint head amounted to $41 \mathrm{~mm}$. The Rescivial area is presented in the form of a macro preparation of rounded form, with pseudo-capsule, forms in diameter of $3.5 \mathrm{~cm}$, on section there is an intraossetic lesion of a particular end more than 1.0 SM and subtotal defeat of a bone during (Figure 5).

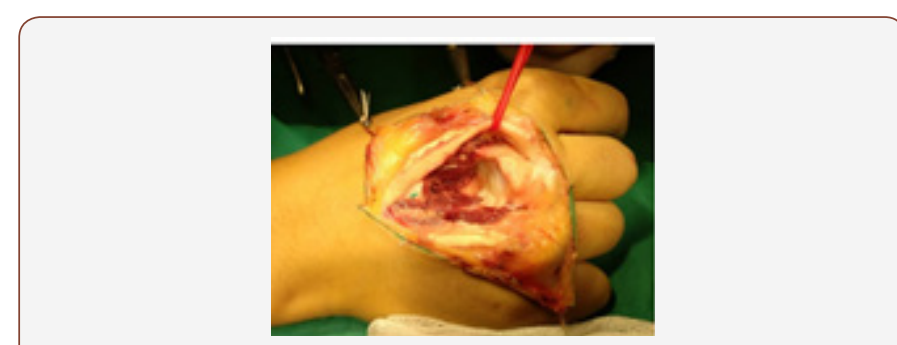

Figure 4: Type of bed after removing the block of affected segment III metacarpal bone.

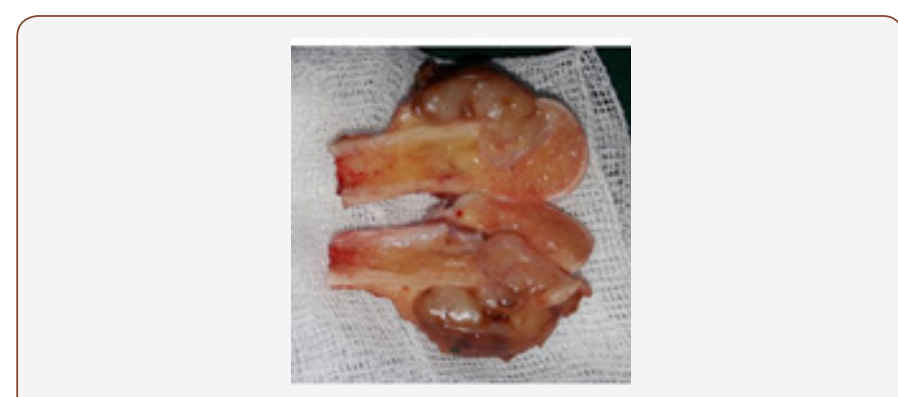

Figure 5: The type of microproduct of the Reseccian segment of the 3rd metacarpal bone on the section.

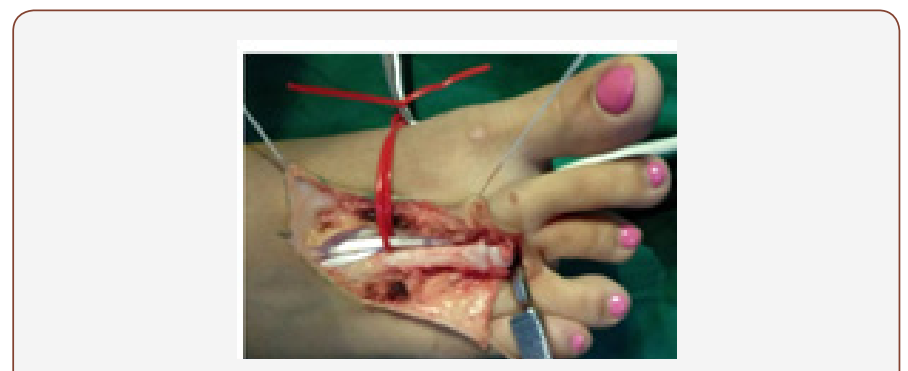

Figure 6: Preparation of the donor avculular autograft III metatarsal bone before and after its discharge.

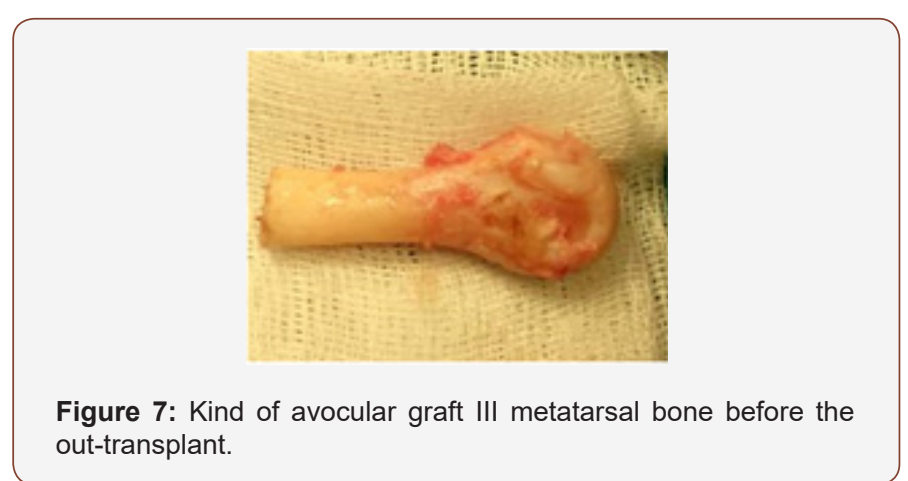

At the same time, another team of reconstructive surgeons began mobilizing donor transplantation. The same incision over the projections of the location of The III metatarsal bone of the right foot is separated and the distal joint head is mobilized (Figure 6). The length of the donor graft also amounted to $41 \mathrm{~mm}$ (Figure 7). After transferring the transplant to the donor area, the base of the main Phalange III of the toe is fixed by filing the capsule and collateral ligaments to the adjacent metatarsal-phalange joints II and IV Fingers. 
The Avocular graft III of the metatarsal bone is fixed to the base of the remainder of the third metacarpal bone with the help of a kirshner needle. The capsule of the joint of the ushite in the circular direction with the help of the atravmatic threads (Figure 8).

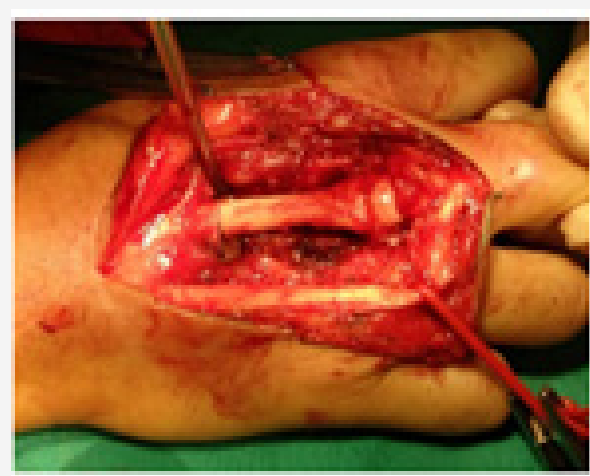

Figure 8: Type of Autotransplantata after laying in the donor bed. Anatomical bone-articular defect of the 3rd metacarpal bone is completely replenished by Autograft III metatarsal bone.

The duration of the operation amounted to 1 hour $45 \mathrm{~min}$. There were no complications in the near postoperative period. The next postoperative period proceeded smoothly, there were no signs of rejection of transplanted transplant, all wounds were healed by primary tension. Histological conclusion Osteoblistalostoma (put a picture of a microscopic picture).

\section{Discussion}

As described above, the giant-cell osteoclastoma III of the metacarpal bone is a rare localization of the tumor. So far, the question of choosing the optimal method of surgical treatment has not found its final solution. At present, along with the supporters of radical resection of the affected bone segment, the practice of curettage with filling of the defect with avocular autografts of bones taken from the cortical plate of the tibia and the crest of the iliac Bone [7-9]. However, radical resection of the tumor in the form of a block of the affected area with a one-moment replacement of the bone-joint defect is a common standard, aimed at eliminating the risk of local recurrence $[3,5,12,14,15]$

As a donor transplant is proposed to use integral autografts of a small-tibia bone [12], III metatarsal Bones [14, 15], less frequently, allo-grafts, titanium plates, etc. Materials $[6,10,11]$. After extensive radical resection of the whole metacarpal bone together with the Pystno-phalanic articulation on the recurrence of the tumor is recommended the use of free vascularized grafts III metatarsal Bone [15]. The combined treatment of surgical rehabilitation of the hearth osteoblopklistoma of the metacarpal bone together with pre-or postoperative irradiation is controversial and has not found its final clinical solution $[7,9]$.

In the conditions of the Republic of Tajikistan earlier was widely applied curettage of bone tissue with filling of the crushed fragments of autologous bone tissue, and after radical resection of metacarpal bone plastic reparation was left on the second stage, fate which remained unknown.
This operation was possible due to joint work of oncologists together with reconstructive-plastic surgeons. The choice of transplant is dictated by the generalization of literary data of the results of research on the use of various grafts, simplicity of technical execution, minimal donor damage.

\section{Conclusion}

When the giant-cell tumor is localized in the metacarpals, the radical blogoid excision is the optimal approach to prevent local relapses. Use of bone-articular avocular graft III the metatarsal bone makes it almost ideal to compensate for a similar defect in the metacarpal bone. The donor defect after the transplant is accompanied by minimal donor losses and does not lead to a disturbance of the foot function. Received Optimal functional and aesthetic results with the complete restoration of the lost anatomy.

\section{Acknowledgement}

None.

\section{Conflicts of Interest}

No conflicts of interest.

\section{References}

1. Kabul C Saikia, Kabul C Saikia, Sanjeev K Bhuyan, Firoz Ahmed, Debashish Chanda (2011) Giant cell tumor of the metacarpal bones. Indian J Orthop 45(5): 475-478.

2. Averill RM, Smith RJ, Campbell CJ (1980) Giant cell tumours of the bones of the hand. J Hand Surg Am 5: 39-50.

3. Williams J, Hodari A, Janevski P, Siddiqui A (2010) Recurrence of giant cell tumors in the hand: A prospective study. J Hand Surg Am 35(3): 451456.

4. Slesarencko YA, Sampson SP, Gould ES (2005) Giant cell tumour of the distal phalanx of hand. Hand Surg 10(2-3): 289-291.

5. Ozalp T, Yercan H, Okçu G, Ozdemir O, Coskunol E, et al. (2007) Giant cell tumour of hand: Midterm results in five patients. Rev Chir Orthop Reparatrice Appar Mot 93(8): 842- 847.

6. Smith RJ, Brushart TM (1985) Allograft bone for metacarpal reconstruction. J Hand Surg Am 10(3): 325-334.

7. Shlihtunov EA, Loud NG, Fedorenko II, Valshonok ON (2013) Osteoblalostomoma of the third metacarpal bone in the patient with secondary lymphedema of the upper limb. Case out of practice. News of surgery 21(2): 105-110

8. Kuftyrev LM, Kuftyrev LM (2004) Autoplasty postresection defects of tubular bones of a brush at the treatment of benign tumors and tumorlike diseases with the use of the Chresbone osté-osynthesis. The genius of orthopedics. 2: 20-25.

9. Dekalo VP, Dekalo VP, Tolstik AN (2006) Hand Surgery: History, modern achievements, problems and prospects of development News of surgery 14(4): 26-36.

10. Patradul A, Kitidumrongsook P, Parkpian V, Ngarmukos C (2001) Allograft replacement in giant cell tumour of the hand. Hand Sur 6(1): 59-65.

11. Thipachart Punyaratabandhu, Boonrat Lohwongwatana, Chedtha Puncreobutr, Arkaphat Kosiyatrakul, Puwadon Veerapan, et al. (2017) A Patient-Matched Entire First Metacarpal Prosthesis in Treatment of Giant Cell Tumor of Bone. Case Rep Orthop.

12. Jones NF, Dickinson BP, Hansen SL (2012) Reconstruction of an entire metacarpal and metacarpophalangeal joint using a fibular osteocutaneous free flap and silicone arthroplasty. J Hand Surg Am 37(2): $310-315$ 
13. Mendenhall WM, Zlotecki RA, Scarborough MT, Gibbs CP, Mendenhall NP (2006) Giant cell tumor of bone. Am J Clin Oncol 29(1): 96-99.

14. Saikat Sau (2016) Reconstruction of metacarpal bone giant cell tumor by metatarsal bone. Int J Res Orthop 2(1): 23-35.
15. Kotwal PP, Nagaraj C, Gupta V (2008) Vascularised joint transfer in the management of recurrent giant cell tumour of the second metacarpal. J Hand Surg Eur 33(3): 314-316. 